\title{
AVALIAÇÃO DA MORFOLOGIA INTERNA DE SEMENTES DE Acca sellowiana O. Berg POR MEIO DE ANÁLISE DE IMAGENS ${ }^{1}$
}

\author{
VANESSA NEUMANN SILVA², MARCELO BENEVENGA SARMENTO 3 , \\ ANA CAROLINA SILVEIRA ${ }^{4}$, CLARISSA SANTOS SILVA ${ }^{5}$, SILVIO MOURE CICERO ${ }^{6}$
}

RESUMO- Acca sellowiana O. (Berg) Burret é uma fruteira nativa da região Sul do Brasil e do Uruguai, que apresenta grande potencial de uso na recuperação de áreas degradadas. O objetivo deste trabalho foi avaliar a morfologia interna de sementes de Acca sellowiana O. Berg por meio da análise de imagens de raios X e relacionar os resultados com a germinação das sementes. Sementes de Acca sellowiana O. Berg, representadas por três lotes, foram analisadas pelo teste de raios $\mathrm{X}$ e, posteriormente, conduzidas ao teste de germinação, com avaliação aos 44 dias após a semeadura. As imagens de raios $\mathrm{X}$ foram analisadas com o software ImageJ. A análise das imagens radiográficas de sementes de Acca sellowiana permite a mensuração das áreas internas livres, assim como a determinação da relação entre estas e a germinação. Danos internos detectados por meio de raios $\mathrm{X}$ afetam a germinação das sementes.

Termos para indexação: raios $X$, imagens, danos.

\section{Acca sellowiana O. Berg SEED MORPHOLOGY EVALUATION BY IMAGE ANALYSIS}

\begin{abstract}
Acca sellowiana O. (Berg ) Burret is a species native from southern of Brazil and Uruguay which has great potential for use in the recovery of native forests and degraded areas. The aim of this study was to evaluate the morphology of Acca sellowiana $\mathrm{O}$. Berg seeds by analysis of X-ray images and correlate the results with seed germination. Acca sellowiana O. Berg seeds, represented by three lots, were analyzed by X-ray test and later the same seeds were submitted to the germination test, with assessment at 44 days after sowing. X-ray images were analyzed with ImageJ software. X-ray test allows Acca sellowiana internal morphology seeds visualization. Seed image analysis allows the measurement of internal seed areas and assists in the study of relationships between seed morphology and germination. The seed internal free space and the presence of damages can affect germination.
\end{abstract}

Index terms: X-ray, images, damage

1(Trabalho 149-13). Recebido em: 04-04-2013. Aceito para publicação em: 22-11-2013.

${ }^{2}$ Eng. Agr., Dra ., Universidade Federal do Pampa, Campus de Itaqui, Itaqui-RS. E-mail: vnpel@yahoo.com.br

${ }^{3}$ Eng. Agr., Dr., Universidade Federal do Pampa, Campus de Dom Pedrito, Dom Pedrito-RS. E-mail: marcelobs05@hotmail.com

${ }^{4}$ Eng. Agr., Dra., Universidade da Região da Campanha, Bagé-RS. E-mail: acsilveiras@yahoo.com.br

${ }^{5}$ Bióloga, Dra., Universidade da Região da Campanha, Bagé-RS. E-mail: clarissas_s@hotmail.com

${ }^{6}$ Eng. Agr., Dr., Universidade de São Paulo, Piracicaba-SP. E-mail: smcicero@usp.br 


\section{'INTRODUÇÃO}

Acca sellowiana O. Berg é uma fruteira nativa da região Sul do Brasil e Nordeste do Uruguai, conhecida regionalmente por goiabeiraserrana ou feijoa e, no Uruguai, como guayabo del país (DUCROQUET et al., 2000), a qual vem despertando grande interesse econômico devido ao sabor exótico de seus frutos. Além disso, apresenta grande potencial de uso ornamental, paisagístico e para recuperação de áreas degradadas.

Apesar da importância desta espécie, existem poucas informações a respeito de aspectos fisiológicos, morfológicos e demais características que influenciam sobre a germinação e a qualidade de sementes.

Atualmente, a análise de imagens de sementes e plântulas tem-se mostrado eficiente para a avaliação dos componentes fisiológicos e físicos de sementes, que influenciam na qualidade dos lotes. Dentre as técnicas disponíveis, o teste de raios $\mathrm{X}$ tem-se revelado eficiente na análise da morfologia interna de sementes, possibilitando o estudo da relação entre essa característica e o seu potencial fisiológico

$\mathrm{O}$ método consiste em expor as sementes a uma fonte de baixa energia de raios $\mathrm{X}$ e a um filme fotossensível. Ao atravessarem as sementes e atingirem o filme, os raios permitem a formação de uma imagem latente, caracterizada por diferentes graus de sombras e luz. O princípio da técnica é definido pela absorção de raios $\mathrm{X}$ em diferentes quantidades pelos tecidos das sementes, em função de sua estrutura, composição e densidade, além do tempo de exposição à radiação (ISTA, 2004).

Considerando-se que as espécies florestais são caracterizadas por grande ocorrência de predação, sementes vazias e má-formação do embrião, bem como apresentam grande variabilidade genética e demandam longo tempo para a obtenção dos resultados do teste de germinação (MASETTO et al., 2008), o teste de raios X, por ser rápido e não destrutivo, pode ser uma alternativa interessante para avaliar a qualidade de sementes destas espécies.

Várias pesquisas têm demonstrado que a análise de imagens de raios X possibilita a identificação de danos que afetam a qualidade de sementes de espécies florestais, como Ginkgo biloba (SALINAS et al., 2012), Tabebuia heptaphylla (AMARAL et al., 2011), Xylopia aromatica (SOCOLOWSKI et al., 2011), Tecoma stans (SOCOLOWSKI et al., 2008), Eremanthus erythropappus (FEITOSA et al., 2009), Cedrela fissilis (MASSETO et al., 2008), Platypodium elegans (SOUZA et al., 2008), Cecropia pachystachya (PUPIM et al., 2008), Eugenia pleurantha (MASSETO et al., 2007) e Tabebuia serratifolia e Tabebuia impetiginosa (OLIVEIRA et al., 2004), entre outras.

Além disso, outra característica passível de avaliação por meio de análise de imagens de raios $\mathrm{X}$, que possivelmente está relacionada com o desempenho das sementes, é o tamanho do embrião, que pode ser definido com a relação entre desenvolvimento embrionário e o espaço disponível na cavidade interna da semente. Socolowski e Cicero (2008) verificaram que a capacidade germinativa das sementes de Tecoma stans é maior naquelas com embriões mais desenvolvidos ou com pequenos danos. Em outras pesquisas, também foi verificada a eficiência da análise de imagens de raios $\mathrm{X}$ para a avaliação da morfologia interna de sementes e a associação destes resultados com a germinação e o vigor, como para sementes de aroeira (MACHADO; CICERO, 2003), Cecropia pachystachya Trec. (PUPIM et al., 2008), pimentão (GAGLIARDI; MARCOS FILHO, 2011), berinjela (SILVA et al., 2012), melão, abóbora e melancia (GOMES JÚNIOR et al., 2012), entre outras. Porém, na maioria dos casos, essa classificação é realizada de forma visual, sendo necessários parâmetros mais precisos para desenvolver modelos mais consistentes de avaliação, para definir categorias de extensão do desenvolvimento embrionário ou espaço livre no interior das sementes (MARCOS FILHO et al., 2010).

Neste contexto, Dell'Áquilla (2007) verificou que sementes de pimentão com áreas internas livres maiores que $2.7 \%$ tiveram aumento progressivo de plântulas anormais e sementes mortas no teste de germinação. No entanto, para sementes de Acca sellowiana $\mathrm{O}$. Berg, não existem informações na literatura quanto a este aspecto.

Desta forma, o objetivo deste trabalho foi avaliar a morfologia interna de sementes de Acca sellowiana O. Berg por meio da análise de imagens de raios $\mathrm{X}$ e relacionar os resultados com a germinação das sementes.

\section{MATERIAL E MÉTODOS}

A pesquisa foi conduzida nos Laboratórios de Análise de Imagens, do Departamento de Produção Vegetal da Escola Superior de Agricultura "Luiz de Queiroz" da Universidade de São Paulo, em Piracicaba-SP e no Laboratório de Sementes do Instituto Biotecnológico de Reprodução Vegetal da Universidade da Região da Campanha, em Bagé-RS .

Foram utilizados três lotes de sementes de Acca sellowiana O. Berg, obtidos do Banco de 
Germoplasma da Empresa de Pesquisa Agropecuária e Extensão Rural de Santa Catarina (Epagri), os quais estavam armazenados em sacos de papel em câmara fria $\left(15-18^{\circ} \mathrm{C} / 45-50 \% \mathrm{UR}\right)$. As sementes foram analisadas pelo teste de raios $\mathrm{X}$ e, posteriormente, foram conduzidas ao teste de germinação, doze meses após a colheita dos frutos e a extração das sementes.

Para o teste de raios $\mathrm{X}$, foram utilizadas cinco repetições de 20 sementes, colocadas sobre uma fita adesiva transparente (dupla face) e fixadas em lâmina plástica transparente; as sementes foram numeradas de acordo com a posição ocupada na lâmina, de maneira que pudessem ser identificadas em determinações posteriores. A lâmina plástica foi colocada no interior do equipamento digital de raios X, marca Faxitron ${ }^{\circledR}$, modelo MX-20 DC-12, acoplado a um computador Core 2 Duo $(3.16 \mathrm{GHz}$, 2 GB de memória RAM, disco rígido de $160 \mathrm{~GB}$ ) e monitor MultiSync (LCD1990SX de 17 polegadas) e submetida à radiação por 20 segundos a $20 \mathrm{kV}$. Em seguida, as imagens geradas foram salvas no disco rígido do computador para sua análise. As sementes foram retiradas da lâmina transparente e transferidas para bandeja acrílica com células individuais, numerando-se na mesma ordem em que estavam nas imagens de raios X. Após esse procedimento, foram conduzidas ao teste de germinação.

$\mathrm{O}$ teste de germinação foi realizado sobre papel toalha umedecido com água destilada na proporção equivalente a 2,5 vezes a massa do papel. As sementes, previamente numeradas, foram desinfestadas com solução de hipoclorito de sódio a $1 \%$ de cloro ativo, por três minutos, enxaguadas com água destilada e, então, distribuídas sobre duas folhas de papel germitest e cobertas com mais uma folha dentro de caixas plásticas $(110 \times 110 \times 35 \mathrm{~mm}) \mathrm{e}$ levadas ao germinador a $20^{\circ} \mathrm{C}$, com 16 horas de luz; a avaliação foi realizada 44 dias após a semeadura (SARMENTO, 2012). As plântulas normais, anormais e as sementes mortas foram retiradas do substrato e fotografadas com auxílio de uma câmera fotográfica digital. As imagens foram salvas no disco rígido do computador para posterior análise.

As imagens das sementes radiografadas foram salvas no formato tiff e analisadas com o software ImageJ, adaptando-se metodologia de análise anteriormente utilizada em outras pesquisas para medição de área foliar (SOUZA NETO, 2009), conforme exemplo ilustrado nas Figuras 1 e 2. As etapas da análise no referido programa foram assim executadas: abertura da imagem (Figura 1A), que deve estar preferencialmente no formato tiff, e sua conversão para o tipo escala de cinza (Figura 1B); deve-se proceder à seleção da área de interesse para a análise, e neste caso realizou-se a análise de cada semente de forma individualizada, delimitando-se cada uma, para que o programa efetuasse a análise (Figura 1C) e logo após realizou-se a seleção da escala que foi utilizada para a calibração da imagem (Figura 1D), sendo que, neste trabalho, foi considerado o valor de pixels em cada imagem como referência, que foi de 2368 X 2340 pixels (Figura 1E); após, foi realizada a escolha dos parâmetros a serem mensurados (Figura 1F), sendo escolhidos como a área do objeto, o perímetro e a área percentual ( fraction area), a qual representa as áreas livres internas das sementes (Figura 2A); após, foi realizado o ajuste de cores, para a separação das áreas de interesse dos demais contituintes da imagem (Figuras 2B, 2C e 2D); por fim, foi efetuada a mensuração dos parâmetros (Figura 2E) e a obtenção dos resultados (Figura 2F). Todos os procedimentos (Figura 2A a $2 \mathrm{~F}$ ) foram executados manualmente para cada semente das amostras.

Um exemplo de análise no ImageJ pode ser observado na Figura 3A. Para facilitar a discussão dos resultados, foi calculado o valor médio da área livre da cavidade interna das sementes na amostra de 100 sementes e o desvio-padrão para cada lote. Com base nestes resultados, foram atribuídas três categorias para classificar as sementes, conforme descrição a seguir: a) categoria 1: sementes com área livre inferior ao valor da média menos um desviopadrão; b) categoria 2: sementes que tiveram área livre compreendida entre a média menos um desviopadrão e a média; c) categoria 3: sementes com área livre maior que a média mais um desvio-padrão. Como poucas sementes tiveram danos (malformação de suas partes e/ou tecidos deteriorados), optouse por fazer o estudo focado na relação entre o preenchimento da cavidade interna de sementes e a germinação, e apresentar os casos isolados de danos. Para auxiliar no entendimento da relação entre morfologia de sementes e a germinação, foi calculada a correlação entre a área livre das sementes e o percentual de plântulas anormais obtidas no teste de germinação.

\section{RESULTADOS E DISCUSSÃO}

A análise das imagens de raios $\mathrm{X}$ permitiu observar a morfologia das sementes de Acca sellowiana e identificar áreas livres internas, assim como danos, os quais podem prejudicar a germinação. Áreas livres ou vazias no interior das sementes foram visualizadas nos três lotes avaliados, como no exemplo da Figura 3B. As áreas escuras 
representam ausência de tecidos ou baixa densidade dos mesmos, os quais impõem menor restrição à passagem dos raios $\mathrm{X}$ e, com isso, provocam $\mathrm{o}$ escurecimento da imagem.

A análise das imagens radiográficas com o software ImageJ possibilitou a mensuração das áreas livres internas das sementes e, desta forma, permitiu a separação das sementes em diferentes categorias, auxiliando no estudo da relação entre a morfologia interna das sementes e a germinação. Esse resultado é interessante, pois até o presente momento somente dois softwares são indicados na literatura para esse tipo de análise, o Tomato Analyzer ${ }^{\circledR}$ (MARCOS FILHO et al., 2010) e o Image ProPlus ${ }^{\circledR}$ (DELL'ÁQUILA, 2007; SILVA et al., 2012), sendo que o Tomato Analyzer é mais indicado para sementes que não possuem endosperma (MARCOS FILHO et al., 2010); portanto, os resultados do presente trabalho indicam mais uma alternativa para pesquisas nesta linha de estudo, o que é muito interessante, pois métodos computadorizados que utilizam alta velocidade de captura e processamento de imagens são as técnicas mais avançadas que podem prover alto nível de eficiência para análise de qualidade de sementes (DELL'ÁQUILA, 2009).

Com base nos resultados obtidos na análise das imagens com o software ImageJ, constatou-se que as sementes dos lotes 1 e 2 tiveram área livre interna média de $7 \%$ em relação à área total da semente, ao passo que, nas sementes do lote 3 , esse valor foi maior, sendo de 9\% (Tabela 1). A distribuição das sementes quanto à área livre dentro de cada lote pode ser visualizada na Figura 4, na qual se observa que a maioria das sementes dos lotes 1 e 2 tiveram valores de área livre inferiores a 10\% em relação à área total da semente, ao passo que, no lote 3 , várias sementes tiveram valores de áreas livres acima de $10 \% \mathrm{e}$, em alguns casos, chegando aos $20 \%$.

As diferenças de área livre nas sementes dentro de cada lote podem ocorrer devido à desuniformidade de maturação de sementes, comuns em espécies florestais, especialmente considerandose as espécies nativas, as quais, na maioria dos casos, não sofreram intenso processo de melhoramento genético e domesticação, e, portanto, possuem florescimento e produção de frutos e sementes muito desuniformes. Segundo Ducroquet e Hickel (1991), a maturação dos frutos de Acca sellowiana inicia-se no final de fevereiro e estende-se até o início de junho no Estado de Santa Catarina, local de produção das sementes utilizadas nesta pesquisa.

A presença de áreas livres no interior da semente pode prejudicar o potencial germinativo, pois estas podem significar menor quantidade de substâncias de reservas armazenadas, as quais são essenciais para o fornecimento de energia para os processos iniciais de germinação, pois a síntese de proteínas e a atividade respiratória inicial envolvem componentes armazenados durante a maturação das sementes (NONOGAKI et al., 2010). Vários trabalhos de pesquisa relatam que sementes parcialmente formadas, com áreas livres internas, não foram capazes de originar plântulas normais no teste de germinação, como para Cecropia pachystachya Trec (PUPIM et al., 2008) e aroeira (MACHADO; CICERO, 2003). Para pimentão, Dell'Áquila (2007) constatou que, quando as sementes tinham áreas livres maiores que 2,7\%, em relação à sua área total, na maioria dos casos, originaram plântulas anormais ou não germinaram.

Mas a maior área livre interna nem sempre prejudicou a germinação de sementes, como a de berinjela (SILVA et al., 2012).

A relação entre a morfologia interna das sementes de Acca sellowiana, considerando-se as áreas internas livres, e a germinação ocorreu de forma diferenciada para os três lotes avaliados (Tabela 2); para o lote 1, áreas livres maiores que $7,05 \%$ prejudicaram o potencial germinativo das sementes; porém, para os lotes 2 e 3, áreas livres acima de $3,84 \%$ e $5,6 \%$, respectivamente, já foram suficientes para reduzir a germinação das sementes.

É possível que o menor volume de tecidos de reserva possa prejudicar a germinação, como foi relatado por Socolowski et al. (2011) para sementes de Xylopia aromatica. Esses autores verificaram, por meio da análise de imagens de raios $\mathrm{X}$, que sementes de maior massa possuíam endosperma bem formado e que houve relação direta entre esta característica e os resultados de emergência de plântulas. Constataram, ainda, que as sementes de maior massa germinaram de forma mais rápida e em maior proporção que sementes de menor massa.

Entretanto, outros fatores não relacionados diretamente com a morfologia interna de sementes, como balanço hormonal e atividade enzimática, influenciam na reorganização das estruturas celulares da semente durante a embebição, na síntese e na degradação de compostos durante a mobilização das reservas armazenadas nas sementes, assim como na expansão, na divisão e no crescimento celular, que ocorrem durante a germinação (NONOGAKI et al., 2010).

A maioria das sementes de Acca sellowiana com menor área livre (categoria 1) originaram maior percentual de plântulas normais (Tabela 2). Entretanto, é necessário mencionar que houve baixo percentual de sementes classificadas na categoria 1 , 
nos três lotes, e, portanto, a probabilidade de ocorrer maior germinação das sementes desta categoria é maior que nas demais. Observa-se que houve correlação entre o número de sementes com áreas livres internas e o percentual de plântulas anormais na categoria 1 , nos lotes 1 e 2 , assim como na categoria 3 , para os lotes 1 e 3; portanto, nem sempre as áreas livres no interior da semente provocaram a geração de anormalidades nas plântulas (Tabela 2).

É importante enfatizar que o baixo percentual de germinação das sementes das categorias 2 e 3 pode ter ocorrido, também, em função do potencial fisiológico destas, independentemente da área livre, já que poucas sementes apresentaram danos, ao contrário de outras pesquisas relatadas na literatura para sementes de espécies florestais.

Contudo, deve-se mencionar que algumas sementes apresentaram danos, que afetaram a germinação, como pode ser visualizado na Figura 5. Observa-se que os danos na região da radícula, indicados pela seta nas Figuras $5 \mathrm{~B}$ e $5 \mathrm{C}$, resultaram em anormalidade da raiz primária nas plântulas correspondentes (Figuras 5B' e 5C'), ao passo que a semente que não possuía danos em sua estrutura, originou uma plântula normal (Figura 5A'). Em outras pesquisas, foi relatado que danos na estrutura da semente podem prejudicar a germinação, como em aroeira (MACHADO; CICERO, 2003), Eugenia pleurantha (MASSETO et al., 2007), Ocotea pulchella, Persea pyrifolia, Nectandra grandiflora, Nectandra lanceolata e Nectandra nitidula (CARVALHO et al., 2009) e Tabebuia heptaphylla (AMARAL et al., 2011). É possível que o efeito dos danos na germinação ocorra em função da interrupção na translocação de nutrientes do endosperma para o embrião (MENEZES et al., 2012; CICERO; BANZATTO JÚNIOR, 2003).

Diante do exposto, verifica-se que a análise de imagens radiográficas se apresenta como uma alternativa interessante para a identificação de possíveis danos e características como a presença de áreas internas livres nas sementes de Acca sellowiana, as quais podem reduzir o potencial fisiológico dos lotes. O uso de sistemas de análise de imagens, como o relatado no presente trabalho, pode contribuir para o aprimoramento da qualidade de lotes, permitindo a identificação de sementes com menor potencial e o descarte destas antes da comercialização, auxiliando no controle de qualidade.

TABELA 1 - Área livre média (ALM) e desvio-padrão (DP) em cada categoria (C) de morfologia interna de sementes de Acca sellowiana O. Berg. Bagé-RS, 2012.

\begin{tabular}{cccccc} 
& & & \multicolumn{4}{c}{$\mathrm{C}$} \\
Lote & ALM $(\%)$ & & \multicolumn{3}{c}{3} \\
\cline { 4 - 6 } & & & 1 & $3,7701-7,05$ & $>7,05$ \\
1 & 7,05 & 3,28 & $<3,77$ & $3,8401-7,17$ & $>7,17$ \\
2 & 7,17 & 3,33 & $<3,84$ & $5,6201-9,00$ & $>9,001$ \\
3 & 9,00 & 3,38 & $<5,62$ & & \\
\hline
\end{tabular}

TABELA 2 - Percentual de sementes (S) de goiabeira-serrana (Acca sellowiana O. Berg) em cada categoria de morfologia interna $(C)$, de acordo com o software ImageJ, e percentual de plântulas normais obtido no teste de germinação (PN) e de plântulas anormais (PA). Bagé-RS, 2012.

\begin{tabular}{cccccc}
\hline Lote & C & S (\%) & PN (\%) & PA (\%) & Cor* \\
\hline \multirow{3}{*}{1} & 1 & 7 & 43 & 0 & 0,5 \\
& 2 & 54 & 43 & 7 & $-0,87$ \\
& 3 & 39 & 28 & 12 & 0,87 \\
\hline \multirow{2}{*}{2} & 1 & 14 & 50 & 50 & 0,87 \\
& 2 & 44 & 43 & 2 & $-0,5$ \\
& 3 & 42 & 24 & 50 & $-0,5$ \\
\hline \multirow{2}{*}{3} & 1 & 7 & 90 & 0 & -1 \\
& 2 & 45 & 45 & 38 & $-0,5$ \\
& 3 & 48 & 40 & 4 & 1 \\
\hline
\end{tabular}

* Correlação entre a área livre das sementes e o percentual de plântulas anormais obtidas no teste de germinação. 

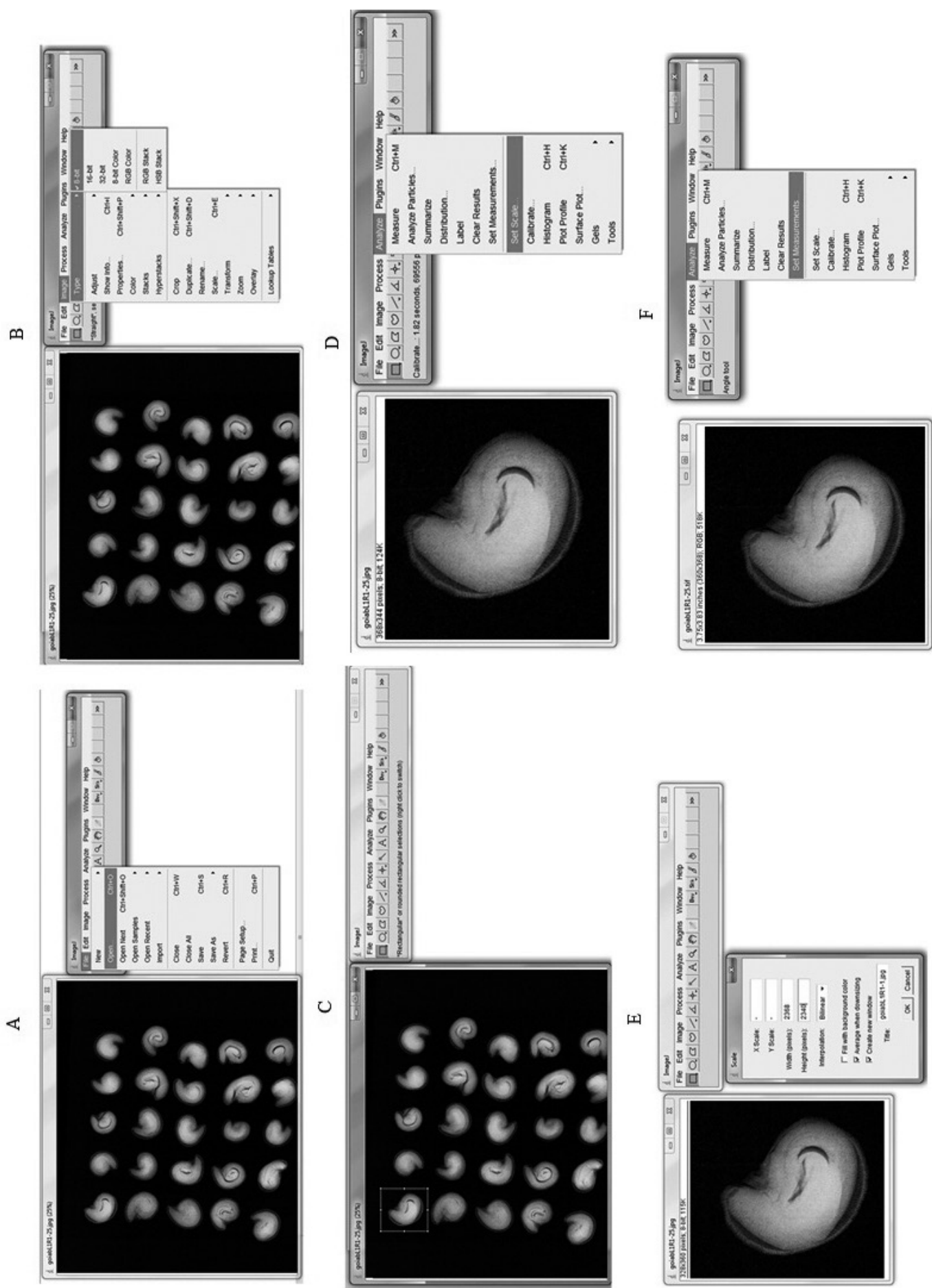

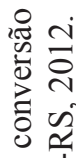
ङ ๓

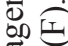
: 준 플 饶 तै 쥴 $\ddot{0}$ ล : 홍 羟 을 욤

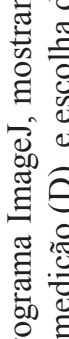
은 음 덩 일 을 ๘ ¿ $\nabla \ddot{\oplus}$ 记 क्ष टี D $\because$ \& 芯 $\cos ^{-\pi} \cdot \pi$

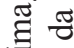
음 : สี $\because \varepsilon$ 응 일 ีㅠㅀ 离刍

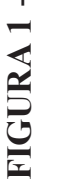


出
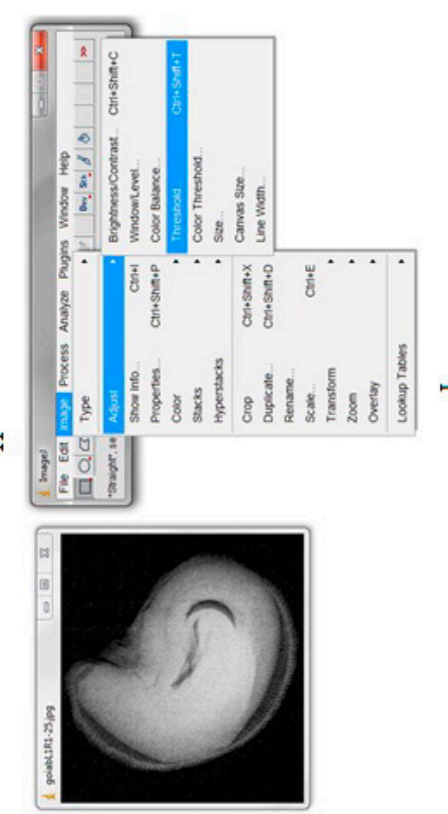

0

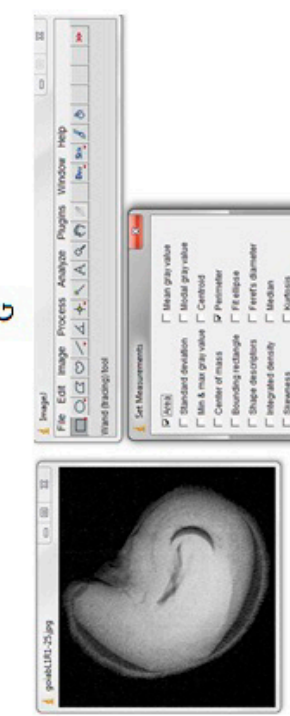

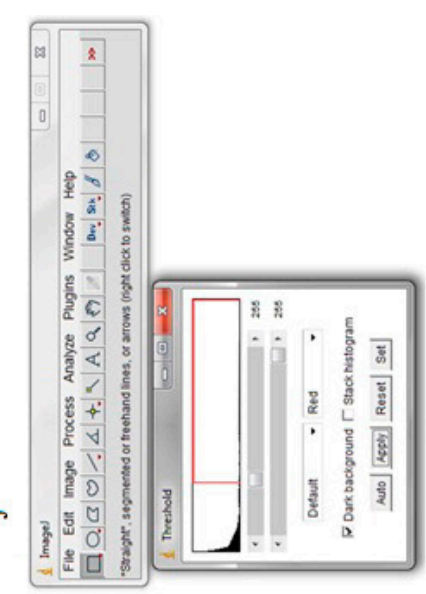
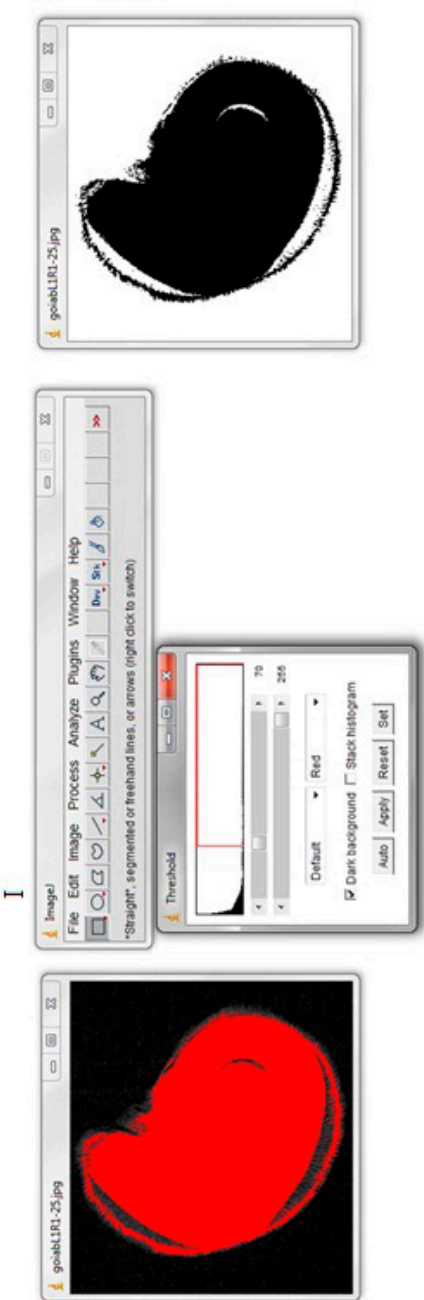

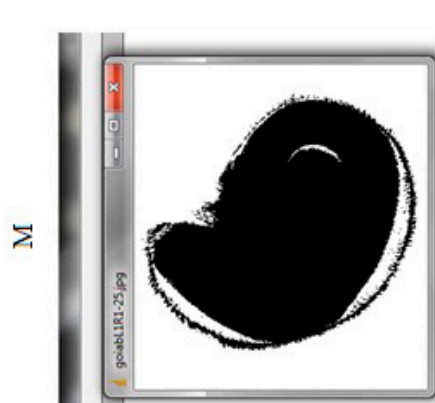

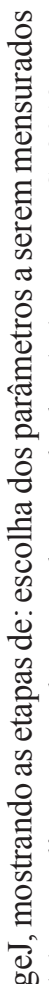

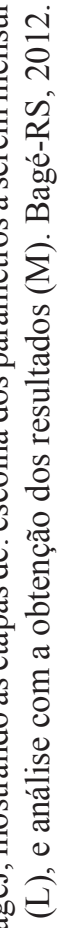
苛
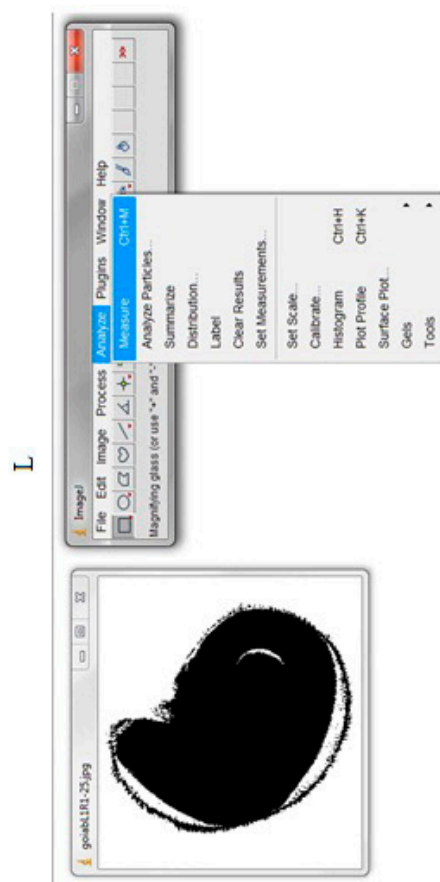

. 胥 कD है, 을 空 วิ 응 త్ర 范 \& कै एँ 远 ¿ D 0 过 논 00 苯 $\frac{\pi}{\pi}$ 证 ส 휴 艺 을 気 II

谒 
A

Results
\begin{tabular}{l|l|l|}
\hline File Edit & Font Results \\
\hline & Area & Perim. \%Area \\
\hline 1 & 14.266 & 1456 \\
7.565 \\
\hline
\end{tabular}
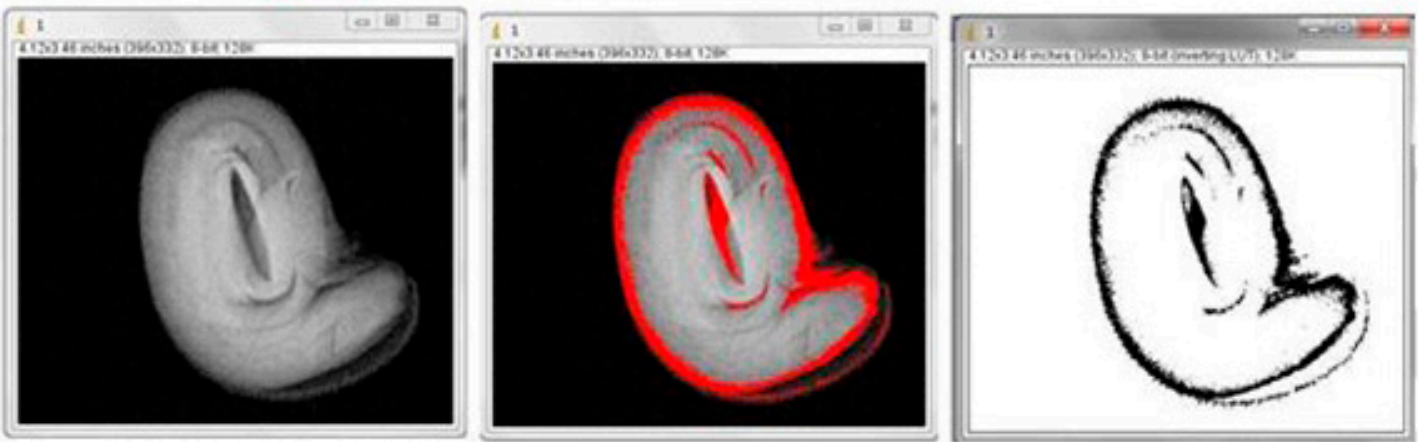

B
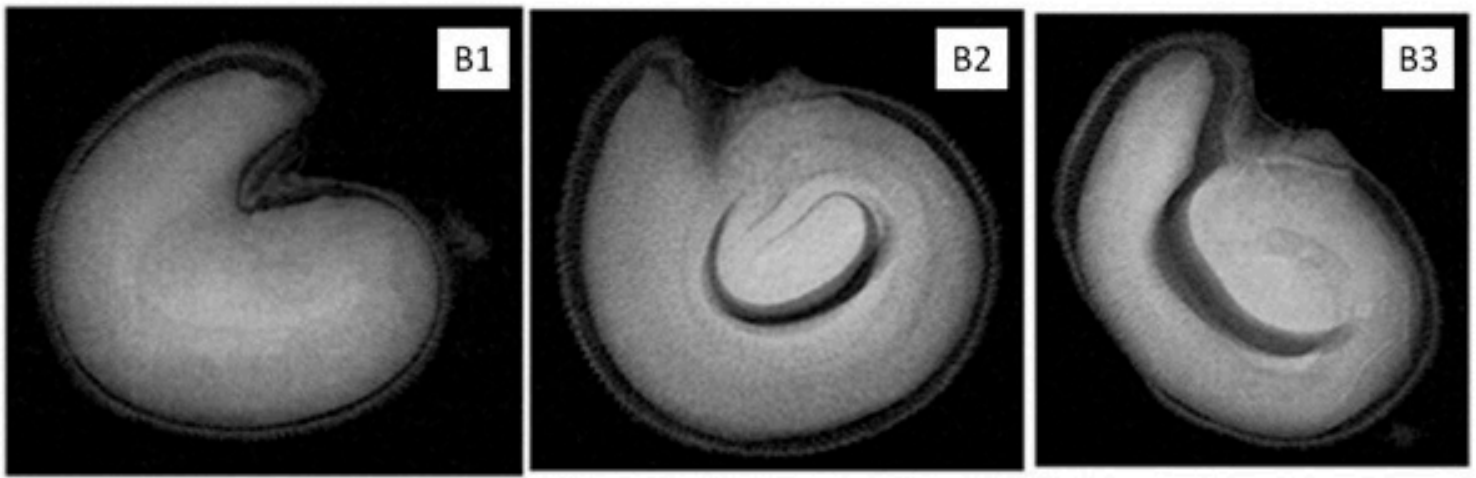

FIGURA 3 - Exemplo de análise de imagens de sementes de Acca sellowiana no programa ImageJ (A), e exemplos de sementes de Acca sellowiana $\mathrm{O}$. Berg com diferenças na área da cavidade interna preenchida pelo embrião e endosperma, categoria 1 (B1), categoria 2 (B2) e categoria 3 (B3). Bagé-RS, 2012. 


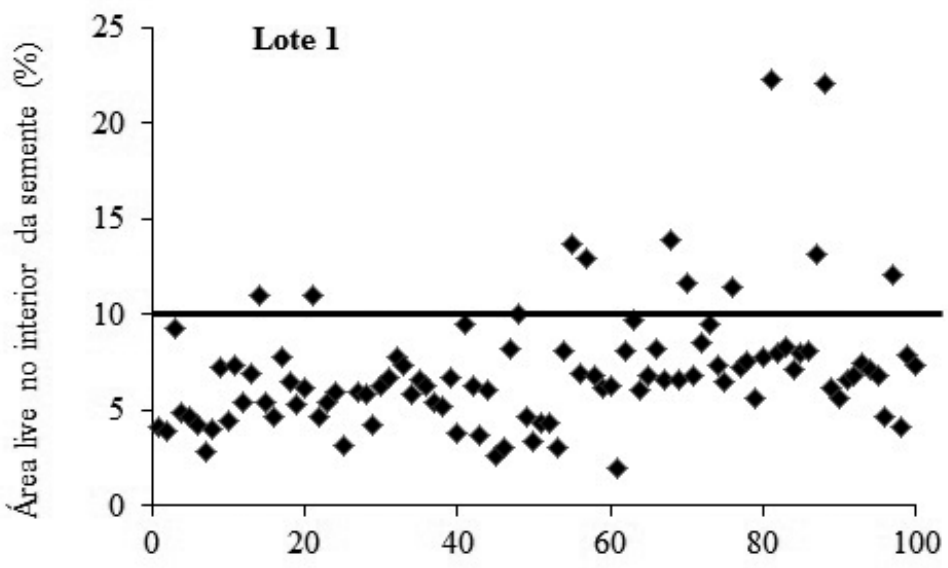

Número de sementes
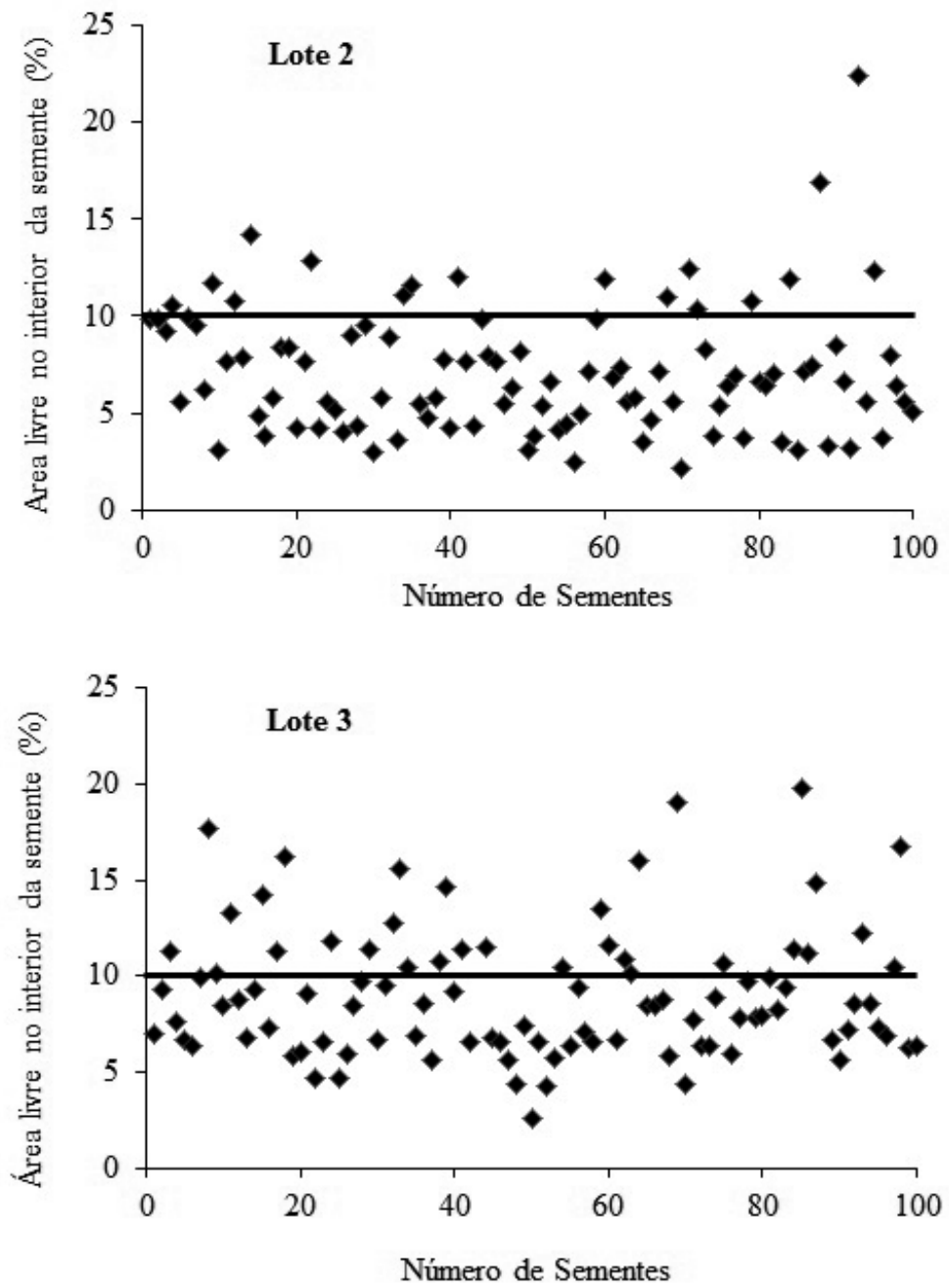

FIGURA 4 - Área (\%) de espaço livre no interior da cavidade de cada semente de Acca sellowiana O. Berg numa amostra de 100 sementes. Bagé-RS, 2012. 

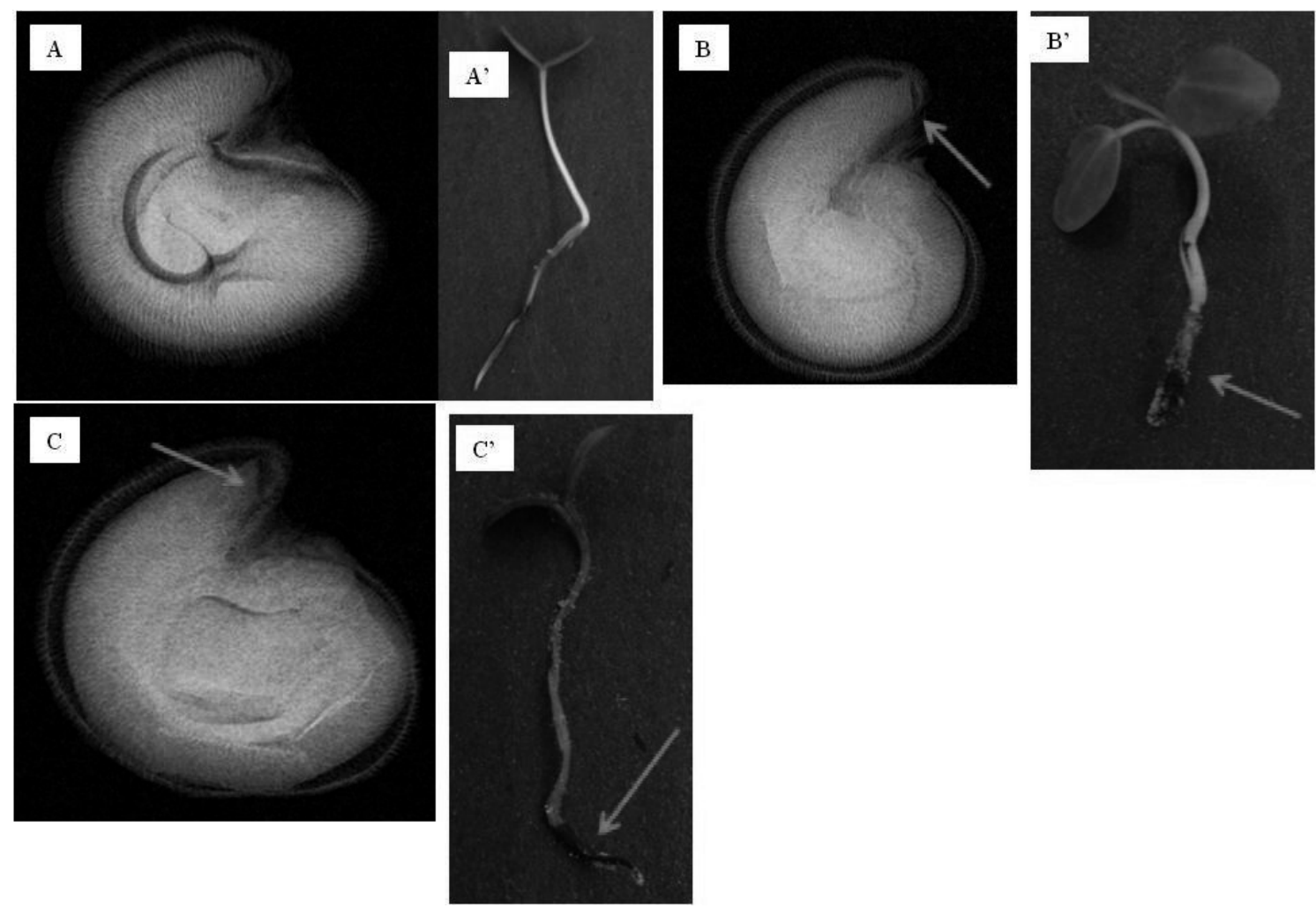

FIGURA 5 - Exemplos de sementes de Acca sellowiana O. Berg sem danos (A), e com danos indicados pela seta (B e C), e suas respectivas plântulas normais (A'), e anormais (B' e C'). Bagé-RS, 2012.

\section{CONCLUSÃO}

A análise das imagens radiográficas de sementes de Acca sellowiana, com o software ImageJ, permite a mensuração das áreas internas livres, assim como a determinação da relação entre estas e a germinação. Danos internos detectados por meio de raios $\mathrm{X}$ afetam a germinação das sementes.

\section{AGRADECIMENTOS}

À Empresa de Pesquisa Agropecuária e Extensão Rural de Santa Catarina (Epagri), pela doação das sementes para a realização desta pesquisa.

\section{REFERÊNCIAS}

AMARAL, J. B.; MARTINS, L.; FORTI, V. A.; CICERO, S. M.; MARCOS FILHO, J. Teste de raios $\mathrm{X}$ para a avaliação do potencial fisiológico de sementes de ipê-roxo. Revista Brasileira de Sementes, Londrina-PR, v. 33, n. 4, p. 601 - 607, 2011.

CARVALHO, L. R.; CARVALHO, M. L. M.; DAVIDE, A. C. Utilização do teste de raios-X na avaliação da qualidade de sementes de espécies florestais de Lauraceae. Revista Brasileira de Sementes, Londrina, v. 31, n. 4, p. 57-66, 2009.

CÍCERO, S. M.; BANZATTO JÚNIOR, H. L. Avaliação do relacionamento entre danos mecânicos e vigor, em sementes de milho, por meio da análise de imagens. Revista Brasileira de Sementes, Pelotas, v. 25 , n. 1 , p. $25-28$, jun. 2003. 
DELL'AQUILA, A. Digital imaging information technology applied to seed germination testing. A review. Agronomy for Sustainable Development, Paris, v.29, p.213 - 221, 2009

DELL'AQUILA, A. Pepper seed germination assessed by combined X-radiography and computeraided imaging analyses. Biologia Plantarum, Praha, v. 51, p. 777-781, 2007.

DUCROQUET, J.P.H.J.; HICKEL, E.R. Fenologia da goiabeira-serrana (Feijoa sellowiana Berg) no alto Vale do Rio do Peixe, Santa Catarina. Revista Brasileira de Fruticultura, Jaboticabal, v.13, n.3, p.313-320, 1991.

DUCROQUET, J. P. J.; HICKEL, E. R.; NODARI, R. O. Goiaba-serrana (Feijoa sellowiana). Jaboticabal: FUNEP, 2000.

FEITOSA, S. S.; DAVIDE, A. C.; TONETTI, O. A. O.; FABRICANTE, J. R.; LUI, J. J. Estudos de viabilidade de sementes de candeia (Eremanthus erythropappus (dc.) macleish) por meio de testes de germinação e raios X. Floresta, Curitiba, v. 39, n. 2, p. 393-399, 2009.

GAGLIARDI, B.; MARCOS FILHO, J. Relationship between germination and bell pepper seed structure assessed by the X-ray test. Scientia Agricola, Piracicaba, v.68, n.4, p.411-416, 2011.

GOMES JÚNIOR, F.G.; YAGUSHI, J.T.; BELINI, U.L.; CICERO, S.M.; TOMAZELLO-FILHO, M. X-ray densitometry to assess internal seed morphology and quality. Seed Science and Technology, Zurich, v.40, p. 102-107, 2012.

ISTA. Rules for seed testing. Zurich: International Seed Testing Association, 2004. 174p.

MACHADO, C. F.; CICERO, S. M. Aroeira-branca (Lithraea molleoides (Vell.) Engl. Anacardiaceae) seed quality evaluation by the X-ray test. Scientia Agricola, Piracicaba, v.60, n.2, p.393-397, 2003.

MARCOS-FILHO, J.; GOMES JUNIOR, F.G.; BENNETT, M.A.; WELLS, A.A.; STIEVE, S. Using tomato analyzer software to determine embryo size in X-rayed seeds. Revista Brasileira de Sementes, Londrina-PR, v.32, n.2, p.146-153, 2010.
MASSETO, T. E.; DAVIDE, A. C.; SILVA, E. A. A.; FARIA, J. R. M. Avaliação da qualidade de sementes de Eugenia pleurantha (Myrtaceae) pelo teste de raios X. Revista Brasileira de Sementes, LondrinaPR, v. 29, n. 3, p.151-155, 2007

MASSETO, T. E.; FARIA, J. M. R.; QUEIROZ, S. E. E. Avaliação da qualidade de sementes de cedro (Cedrela fissilis) pelo teste de raios X. Ciência e Agrotecnologia, Lavras, v. 32, n. 6, p. 1708-1712, 2008.

MENEZES, N. L.; CICERO, S. M.; VILLELA, F. A.; BORTOLOTTO, R. P. Using X rays to evaluate fissures in rice seeds dried artificially. Revista Brasileira de Sementes, Viçosa, MG, v. 34, n.1, p. $70-77,2012$.

NONOGAKI, H.; BASSEL, G. W.; BEWLEY, J. D. Germination-Still a mystery. Plant Science, Limerick, v. 179, p. 574-581, 2010.

OLIVEIRA, L. M.; CARVALHO, M. L. M.; GUIMARÃES, R. M.; MASETTO, T. E. Avaliação da qualidade de sementes de Tabebuia serratifolia Vahl Nich. e T. impetiginosa (Martius ex A. P. de Candolle) Standley pelo teste de raios X. Revista Brasileira de Sementes, Pelotas-RS, v. 26, n.2, p. $138-143,2004$.

PUPIM, T.L.; NOVEMBRE,A.D.L.C.; CARVALHO, M.L.M.; CICERO, S.M. Adequação do teste de raios x para a avaliação da qualidade de sementes de embaúba (Cecropia pachystachya Trec.). Revista Brasileira de Sementes, Londrina-PR, v. 30, n. 2 , p.28-32, 2008.

SALINAS, A. R.; CRAVIOTTO, R. M.; BISARO, V.; GAllO, C. D. V.; ARANGO, M. X-RAY CHARACTERIZATION OF Ginkgo bilobaL. SEEDS USING DIGITAL AND MANUAL MEASUREMENTS. Revista Caatinga, Mossoró, v. 25 , n. 3 , p. 1-7, 2012 .

SARMENTO, M. B. Biometria, crescimento inicial e avaliação da qualidade fisiológica em sementes de goiabeira-serrana (Acca sellowiana O. BERG.). 2012. 78f. Tese (Doutorado em Ciência e Tecnologia de Sementes) - Universidade Federal de Pelotas, Pelotas, 2012. 
SILVA, V. N.; CICERO, S. M.; BENNETT, M. Relationship between eggplant seed morphology and germination. Revista Brasileira de Sementes, Viçosa, MG, v. 34, n. 4, p. 597-604, 2012.

SOCOLOWSKI, F.; CICERO, S. M. Caracterização morfológica de embriões por imagens de raios $\mathrm{x}$ e relação com a massa e a qualidade fisiológica de sementes de tecoma stans L. Juss. Ex Kunth (Bignoniaceae). Revista Brasileira de Sementes, Londrina-PR, v.30, n.2, p.200-208, 2008.

SOCOLOWSKI, F.; CICERO, S. M.; VIEIRA, D. C. M. Seed weight of Xylopia aromatica (Annonaceae): quality evaluation from X-ray and seedling emergence. Scientia Agricola, Piracicaba, v.68, n.6, p.643-646, 2011.
SOUZA, L. A.; REIS, D. N.; SANTOS, J. P.; DAVIDE, A. C. Uso de raios-x na avaliação da qualidade de sementes de Platypodium elegans Vog. Revista Ciência Agronômica, Fortaleza, v. 39, n. 2, p. 343-347, 2008.

SOUZA NETO, A. G. S. Avaliação da área foliar de cinco espécies florestais ocorrentes no semiárido paraibano. 2009. 37f. Monografia (Engenharia Florestal) - Universidade Federal de Campina Grande, Patos, 2009. 